\title{
The Effect of Fruit and Vegetable Intake on Risk for Coronary Heart Disease
}

\section{Citation}

Joshipura, Kaumudi J., Frank B. Hu, JoAnn E. Manson, Meir J. Stampfer, Eric B. Rimm, Frank E. Speizer, Graham Colditz, et al. 2001. "The Effect of Fruit and Vegetable Intake on Risk for Coronary Heart Disease." Annals of Internal Medicine 134 (12): 1106. https:// doi.org/10.7326/0003-4819-134-12-200106190-00010.

\section{Permanent link}

http://nrs.harvard.edu/urn-3:HUL.InstRepos:41254599

\section{Terms of Use}

This article was downloaded from Harvard University's DASH repository, WARNING: This file should NOT have been available for downloading from Harvard University's DASH repository.

\section{Share Your Story}

The Harvard community has made this article openly available.

Please share how this access benefits you. Submit a story.

Accessibility 


\section{The Effect of Fruit and Vegetable Intake on Risk for Coronary Heart Disease}

Kaumudi J. Joshipura, ScD; Frank B. Hu, MD; JoAnn E. Manson, MD; Meir J. Stampfer, MD; Eric B. Rimm, ScD; Frank E. Speizer, MD; Graham Colditz, MD; Alberto Ascherio, MD; Bernard Rosner, PhD; Donna Spiegelman, ScD; and Walter C. Willett, MD

Background: Many constituents of fruits and vegetables may reduce the risk for coronary heart disease, but data on the relationship between fruit and vegetable consumption and risk for coronary heart disease are sparse.

Objective: To evaluate the association of fruit and vegetable consumption with risk for coronary heart disease.

Design: Prospective cohort study.

Setting: The Nurses' Health Study and the Health Professionals' Follow-Up Study.

Participants: 84251 women 34 to 59 years of age who were followed for 14 years and 42148 men 40 to 75 years who were followed for 8 years. All were free of diagnosed cardiovascular disease, cancer, and diabetes at baseline.

Measurements: The main outcome measure was incidence of nonfatal myocardial infarction or fatal coronary heart disease (1127 cases in women and 1063 cases in men). Diet was assessed by using food-frequency questionnaires.
Results: After adjustment for standard cardiovascular risk factors, persons in the highest quintile of fruit and vegetable intake had a relative risk for coronary heart disease of $0.80(95 \% \mathrm{Cl}, 0.69$ to 0.93) compared with those in the lowest quintile of intake. Each 1 -serving/d increase in intake of fruits or vegetables was associated with a $4 \%$ lower risk for coronary heart disease (relative risk, $0.96[\mathrm{Cl}, 0.94$ to 0.99 ]; $P=0.01$, test for trend). Green leafy vegetables (relative risk with 1-serving/d increase, $0.77[\mathrm{Cl}, 0.64$ to 0.93$]$ ), and vitamin $\mathrm{C}$-rich fruits and vegetables (relative risk with 1-serving/d increase, $0.94[\mathrm{Cl}, 0.88$ to 0.99$]$ ) contributed most to the apparent protective effect of total fruit and vegetable intake.

Conclusions: Consumption of fruits and vegetables, particularly green leafy vegetables and vitamin C-rich fruits and vegetables, appears to have a protective effect against coronary heart disease. n several studies, many nutrients in fruits and vegetables, such as dietary fiber, potassium, and antioxidants, have been associated with reduced risk for cardiovascular disease (1-5). However, as reviewed elsewhere (6), most prospective studies that have specifically examined intake of fruits and vegetables in relation to risk for cardiovascular disease have been small, and their results have been inconsistent. Dietary assessments were often crude and available only at baseline, and few studies have examined the effects of specific types of vegetables or fruits. In a recent report (7), we evaluated the association between fruit and vegetable intake and risk for ischemic stroke. We found that persons in the highest quintile of fruit and vegetable intake had a relative risk of 0.69 (95\% CI, 0.52 to 0.92 ) compared with the lowest quintile of intake; moreover, a 1-serving/d increase in fruit or vegetable intake was associated with a 6\% lower risk for ischemic stroke, after controlling for standard cardiovascular risk factors. In the current study, we sought to evaluate the association between intake of overall and specific fruits and vegetables and incidence of coronary heart disease.

\section{Methods}

Study Sample

The samples for this analysis consisted of participants in the Nurses' Health Study (8) and Health Professionals' Follow-Up Study (1). The two studies have similar designs; in both, participants complete mailed questionnaires about medical history, health behaviors, and occurrence of cardiovascular and other outcomes every 2 years. The Nurses' Health Study began in 1976 , when 121700 female registered nurses 30 to 55 years of age were recruited; diet was first assessed in 1980. Health Professionals' Follow-up Study participants were recruited in 1986 and comprise 51529 male health professionals, including dentists, veterinarians, pharmacists, optometrists, osteopaths, and podiatrists, 40 to 75 years of age.

\section{Sample for Analysis}

We excluded participants with incomplete dietary assessments or with previously diagnosed cancer, diabetes or cardiovascular disease that was reported before the first dietary assessment. We followed 84251 eligible 
women during 14 years of follow-up and 42148 eligible men during 8 years follow-up for incidence of coronary heart disease. The rate of follow-up for nonfatal events was $97 \%$ of the total potential person-years of follow-up in both cohorts.

\section{Assessment of Coronary Heart Disease End Points}

Our primary end point was nonfatal myocardial infarction or fatal coronary disease occurring after return of the 1980 questionnaire but before 1 June 1994 in women and after return of the 1986 questionnaire but before 1 January 1994 in men. We sought to review medical records for all such reports. Records were reviewed by physicians who were blinded to the participants' risk factor status. Myocardial infarction was confirmed by using World Health Organization criteria: symptoms plus either diagnostic electrocardiographic changes or elevated levels of cardiac enzymes (9). Infarctions that required hospital admission and for which confirmatory information was obtained by interview or letter, but for which no medical records were available, were designated as "probable." We included all confirmed and probable cases in our analyses because results were the same after probable cases were excluded.

Deaths were identified by using state vital records and the National Death Index or were reported by next of kin and the U.S. postal system. Follow-up for deaths was more than $98 \%$ complete (10). Death certificates along with medical records were used to ascertain cause of death. Fatal coronary disease was categorized as "definite" if 1) it was confirmed by hospital record or autopsy or 2) coronary disease was listed as the cause of death on the certificate, this was the underlying and most plausible cause, and evidence of previous coronary disease was available. We did not rely on the statement of the cause of death on the death certificate alone as providing sufficient confirmation of death due to coronary heart disease. If no medical records were available, we categorized persons in whom coronary heart disease was the underlying cause on the death certificate as "presumed coronary heart disease." Analyses limited to confirmed cases yielded results very similar to those obtained when all cases were included, although with less precision. Persons who experienced sudden death within 1 hour of onset of symptoms and had no plausible cause other than coronary disease were categorized as coronary heart disease cases. Fatal cases of coronary heart disease constituted $30 \%$ of all cases of coronary heart disease among women and $33 \%$ among men.

\section{Dietary Assessment}

Diet was assessed in the Nurses' Health Study in 1980, 1984, 1986, and 1990. A 61-item semi-quantitative food-frequency questionnaire that included 6 fruit items, 11 vegetable items, and 3 potato items was used in 1980. In 1984, the questionnaire was expanded to 126 items that covered 15 fruit items and 28 vegetable items plus potatoes; similar questionnaires were repeated in 1986 and 1990. In the Health Professionals' Followup Study, diet was assessed in 1986 and 1990 by using food-frequency questionnaires very similar to those in the 1984 Nurses' Health Study questionnaire. We excluded women who left 10 or more of the 61 items blank or who had implausible scores for total food intake $(<500$ or $>3500 \mathrm{kcal} / \mathrm{d})$. Men who left 70 or more of the 131 dietary questions blank or who reported daily caloric intake outside the plausible range of 800 to 4200 calories were also excluded.

For each food item, a standard serving size was specified. "Natural" portion sizes-for example, one banana or a small glass of tomato juice-were used whenever possible; otherwise a weight or volume of that item commonly consumed by the U.S. population at one meal was used. On dietary questionnaires, participants reported their average intake of the specified portion size (serving) for each food over the past year. For each food item on the questionnaire, nine responses were possible, ranging from "never or less than once per month" to "six or more times per day." Detailed descriptions of the reproducibility and validity of the food frequency questionnaire for men and women have been published elsewhere (11-13).

Frequencies and portions for the individual food items were converted to average daily intake of each fruit and vegetable item for each participant. The average daily intakes of individual food items were combined to compute total fruit and vegetable intake and intakes of composite fruit and vegetable groups. Definitions of the composite groups (all fruits, all vegetables, citrus fruit, citrus fruit juice, cruciferous vegetables, green leafy vegetables, vitamin $\mathrm{C}$-rich fruits and vegetables, legumes, and potatoes) were modified for our previous study (7)

19 June $2001 \mid$ Annals of Internal Medicine $\mid$ Volume 134 • Number 12 $\mid \mathbf{1 1 0 7}$ 
ARTICLE Effect of Fruit and Vegetable Intake on Risk for Coronary Heart Disease

by using a report by Steinmetz and colleagues (14). Vitamin C-rich fruits and vegetables were defined as those containing more than $30 \mathrm{mg}$ of vitamin $C$ per serving. We did not include potatoes, tofu and soybeans, dried beans, and lentils as vegetables; in addition, condiments such as chili sauce and garlic that had very small portion sizes were not counted in total vegetables. When aggregating items to compute the composite items, we assumed that individual foods for which values were missing implied no intake (15).

\section{Statistical Analysis}

We found 1063 incident cases of coronary heart disease among men and 1127 among women. Persontime for each participant was calculated from the date of return of the 1980 questionnaire in the Nurses' Health Study or the 1986 questionnaire in the Health Professionals' Follow-up Study to the first coronary heart disease event, death, or the cutoff date (1 June 1994 for women and 31 January 1994 for men), whichever occurred first. We excluded participants who reported cardiovascular disease or cancer or diabetes before completion of the baseline dietary questionnaires. Each participant contributed only one end point, and the cohort at risk for each 2-year follow-up period included only those who remained free of reported coronary heart disease at the beginning of each follow-up period.

The study hypotheses were defined before data were collected. The analyses were performed separately in each cohort because of differences in sex and the questionnaires administered to the two cohorts. This approach was selected to achieve better control of confounding. We used pooled logistic regression with 2-year follow-up increments (16) to estimate relative risks (incidence rate ratios) and 95\% CIs within each cohort. Analyses were adjusted for age (5-year categories), smoking (never, former, or current [1 to 14 cigarettes/d, 15 to 24 cigarettes/d, or $\geq 25$ cigarettes/d]), alcohol consumption (five categories in women and seven categories in men), family history of myocardial infarction (before 65 years of age in women and before 60 years of age in men), body mass index (quintiles); use of multivitamin supplements, use of vitamin E, use of aspirin, physical activity (two categories in women and quintiles in men), reported hypertension and hypercholesterolemia, total daily caloric intake (17), and time period (each 2-year follow-up period). Among women, we also controlled for postmenopausal hormone use.

We updated information on diet and risk factors for coronary heart disease over time to better represent long-term patterns $(8,18)$. In the Nurses' Health Study, we used data from the 1980, 1984, 1986, and 1990 questionnaires, and in the Health Professionals' Follow-up Study, we used data from the 1986 and 1990 questionnaires. For each 2-year follow-up period in which events were reported, we computed intake for each composite item as a cumulative average of intake from all available food-frequency questionnaires up to the start of the follow-up period. For participants who experienced angina, coronary artery bypass graft surgery or angioplasty, hypercholesterolemia, hypertension, or diabetes, we stopped updating diet at the beginning of the interval in which they had the outcome because these intermediate end points may influence diet $(8,18)$.

Within each cohort, we computed quintiles for the average daily intake of the fruit and vegetable composite items. The lowest quintile of intake formed the reference category. To minimize the influence of outliers, trends in coronary heart disease risk across quintiles were assessed in logistic models using a continuous variable for the median values of intake for each quintile of the composite item. The relative risk for the continuous measures indicates the change in risk associated with an average increase of 1 serving per day of the standard portion size.

We evaluated associations between fruits and vegetables and risk for coronary heart disease separately among users and nonusers of multivitamin supplements. Nonusers of multivitamins who took other vitamin supplements at baseline were excluded from these subgroup analyses. Nonusers from Health Professionals' Followup Study who took mineral supplements at baseline also were excluded from the subgroup analyses; data on use of mineral supplements were not available in the Nurses' Health Study in 1980. Separate analyses for current smokers and for never or past smokers were conducted to assess whether current smoking influenced the association between intake of fruits and vegetables and risk for coronary heart disease. Similarly, analyses were conducted separately among persons with and without hypertension and those with and without diabetes at baseline.

For the primary analyses, to obtain overall estimates 
for both sexes and to increase power, we combined results from the two cohorts by using the pooling methods proposed by DerSimonian and Laird (19).

\section{Role of the Funding Source}

The funding agencies had no role in the collection, analysis, or interpretation of data or in the decision to submit the paper for publication.

\section{RESULTS}

Persons who consumed more fruits and vegetables were older and generally had healthier lifestyles, as described in detail in our previous report (7). For example, participants who consumed more fruits and vegetables were less likely to smoke and more likely to use multivitamin and vitamin E supplements.

Median total fruit and vegetable intake was 5.8 servings/d for women and 5.1 servings/d for men (Table 1 ). With each 1-serving/d increase in intake, assessed as a linear trend adjusted only for age, caloric intake and time period, the relative risk for coronary heart disease was 0.87 (95\% CI, 0.84 to 0.91$)$ among women and 0.94 (CI, 0.92 to 0.97 ) among men. After additional adjustment for smoking, the relative risk was 0.93 (CI, 0.90 to 0.96 ) among women and 0.96 (CI, 0.93 to 0.99) among men. Further adjustment for additional risk factors produced a relative risk of 0.97 (CI, 0.93 to $1.00)$ among women and 0.96 (CI, 0.93 to 0.99$)$ among men with each 1-serving/d increase in fruit and vegetable intake.

When we controlled further for potential nutritional confounders, including intake of protein, cereal fiber, saturated fat, trans fatty acids, polyunsaturated fat and cholesterol, and meat, addition of trans fatty acids to the model produced the largest change in relative risk associated with a 1-serving/d increase in total fruit and vegetable intake, from 0.96 (CI, 0.94 to 0.99 ) to 0.97 (CI, 0.95 to 1.00 ) (data in men and women combined). Controlling for tofu intake or vegan status, which may reflect overall healthy diets, did not affect the association, and the relative risks and CIs were identical with or without adjustment for meat intake. In analyses adjusted for nondietary risk factors, participants in the top quintile of fruit and vegetable intake had a $20 \%$ lower risk for coronary heart disease (multivariate relative risk, 0.80 [CI, 0.69 to 0.93$]$ ) than did those in the lowest quintile (Table 1). Total fruit intake and total vegetable intake were both individually associated with decreased risk for coronary heart disease. All composite items except legumes, potatoes, and citrus fruit juice were inversely associated with risk for coronary heart disease. The lowest risks were observed in persons with high consumption of green leafy vegetables, cruciferous vegetables, and vitamin $\mathrm{C}$-rich fruit and vegetables. Results were generally similar for men and women.

The Figure shows multivariate relative risk for coronary heart disease associated with increasing intake of fruit and vegetables in men and women combined. Intake of more than 4 servings/d seems to decrease risk for coronary heart disease, and intake of at least 8 servings/d produces a further decrease.

Fruit and vegetable consumption was higher among multivitamin supplement users than nonusers and among nonsmokers than smokers (Table 2). The inverse associations between consumption of citrus fruit, cruciferous vegetables, and total vegetables and risk for coronary heart disease were somewhat stronger among nonsupplement users than supplement users. Although the associations were somewhat weaker and not statistically significant among multiple vitamin users, the number of cases was smaller and the confidence intervals were broad. No striking differences in associations were seen according to smoking status, although the apparent protective effects appeared to be slightly stronger among current smokers than among past smokers and neversmokers.

Results of analyses according to self-reported baseline hypertension status were similar for each 1-serving/d increase among persons with hypertension (relative risk, 0.97 [CI, 0.93 to 1.02$]$ ) and normotensive persons (relative risk, 0.95 [CI, 0.93 to 0.98]). Results of analyses in diabetic persons also supported a protective effect of fruits and vegetables; for an increment of 1 serving/d, the relative risks for coronary heart disease were 0.90 (CI 0.82 to 0.99 ) among diabetic men and 0.93 (CI, 0.85 to 1.02 ) among diabetic women.

Analyses of the individual fruit and vegetables that constituted the composite items did not show that any single fruit or vegetable was strikingly more protective than others in women and men (data not shown). Most items showed null or inverse associations. In general, the findings were consistent with those that may be expected from the composite analyses.

19 June $2001 \mid$ Annals of Internal Medicine $\mid$ Volume 134 • Number $12 \mid 1109$ 
ARTICLE $\mid$ Effect of Fruit and Vegetable Intake on Risk for Coronary Heart Disease

Table 1. Multivariate Relative Risk for Coronary Heart Disease, by Fruit and Vegetable Intake*

\begin{tabular}{|c|c|c|c|c|c|c|c|}
\hline \multirow[t]{2}{*}{ Composite Item } & \multicolumn{5}{|c|}{ Relative Risk for Coronary Heart Disease per Quintile of Intake $(95 \% \mathrm{CI})$} & \multirow{2}{*}{$\begin{array}{l}\text { 1-serving/d } \\
\text { Increase in Fruit } \\
\text { and Vegetable } \\
\text { Intaket }\end{array}$} & \multirow{2}{*}{$\begin{array}{l}\text { Median Fruit and } \\
\text { Vegetable Intake } \\
\text { (Quintile } 1,5 \text { ), } \\
\text { servings/d‡ }\end{array}$} \\
\hline & $1 \S$ & 2 & 3 & 4 & 5 & & \\
\hline Women & 1.0 & 0.91 & 0.88 & 0.86 & 0.80 & 0.97 & $5.82(2.93,10.15)$ \\
\hline Men & 1.0 & 1.01 & 0.95 & 0.87 & 0.80 & 0.96 & $5.07(2.54,9.15)$ \\
\hline Pooled & 1.0 & $0.95(0.84-1.08)$ & $0.92(0.80-1.05)$ & $0.86(0.75-0.99)$ & $0.80(0.69-0.93)$ & $0.96(0.94-0.99)$ & \\
\hline Men & 1.0 & 0.91 & 0.94 & 0.86 & 0.74 & 0.92 & $2.09(0.72,4.33)$ \\
\hline Pooled & 1.0 & $0.87(0.76-0.99)$ & $0.94(0.83-1.08)$ & $0.81(0.70-0.93)$ & $0.80(0.69-0.92)$ & $0.94(0.90-0.98)$ & \\
\hline \multicolumn{8}{|l|}{ All vegetables } \\
\hline Women & 1.0 & 0.89 & 0.92 & 0.80 & 0.77 & 0.93 & $3.34(1.60,6.21)$ \\
\hline Men & 1.0 & 0.96 & 1.00 & 0.94 & 0.87 & 0.97 & $2.83(1.36,5.37)$ \\
\hline Pooled & 1.0 & $0.92(0.81-1.04)$ & $0.96(0.84-1.09)$ & $0.86(0.73-1.02)$ & $0.82(0.71-0.94)$ & $0.95(0.92-0.99)$ & \\
\hline \multicolumn{8}{|l|}{ Total citrus fruit } \\
\hline Men & 1.0 & 1.09 & 1.14 & 0.91 & 1.19 & 1.07 & $0.43(0.00,1.00)$ \\
\hline Pooled & 1.0 & $0.99(0.82-1.20)$ & $1.09(0.95-1.24)$ & $0.90(0.77-1.04)$ & $1.06(0.85-1.32)$ & $1.01(0.90-1.14)$ & \\
\hline \multicolumn{8}{|c|}{ Cruciferous vegetables } \\
\hline Women & 1.0 & 0.90 & 0.85 & 0.83 & 0.80 & 0.76 & $0.42(0.14,0.95)$ \\
\hline Men & 1.0 & 0.87 & 0.95 & 0.86 & 0.93 & 0.96 & $0.4(0.14,1.01)$ \\
\hline Pooled & 1.0 & $0.89(0.78-1.01)$ & $0.89(0.78-1.02)$ & $0.84(0.74-0.97)$ & $0.86(0.75-0.99)$ & $0.86(0.69-1.08)$ & \\
\hline \multicolumn{8}{|c|}{ Green leafy vegetables } \\
\hline Women & 1.0 & 0.92 & 0.89 & 0.74 & 0.69 & 0.70 & $0.73(0.16,1.51)$ \\
\hline Men & 1.0 & 0.89 & 0.93 & 0.89 & 0.76 & 0.84 & $0.59(0.16,1.36)$ \\
\hline Pooled & 1.0 & $0.90(0.79-1.03)$ & $0.91(0.80-1.03)$ & $0.81(0.68-0.97)$ & $0.72(0.63-0.83)$ & $0.77(0.64-0.93)$ & \\
\hline \multicolumn{8}{|c|}{$\begin{array}{c}\text { Vitamin C-rich fruits } \\
\text { and vegetables }\end{array}$} \\
\hline Women & 1.0 & 1.00 & 0.92 & 0.77 & 0.95 & 0.94 & $1.53(0.54,3.08)$ \\
\hline Pooled & 1.0 & $1.19(0.86-1.64)$ & $0.98(0.75-1.30)$ & $1.03(0.56-1.89)$ & $1.15(0.78-1.70)$ & $1.06(0.59-1.89)$ & \\
\hline
\end{tabular}

* Adjusted for age (5-year categories), smoking status (never, former, or current $[1-14,15-24$, or $>24$ cigarettes/d]), alcohol intake (7 categories in men and 5 categories in women), family history of myocardial infarction (age $<60$ years in men and $<65$ years in women), body mass index (quintiles), vitamin supplement use, vitamin $\mathrm{E}$ use, physical activity, aspirin use, 2-year follow-up period, presence of hypertension, presence of hypercholesterolemia, total daily caloric intake, and postmenopausal hormone use (among women). Among women, there were 580404 person-years of follow-up and 1127 cases of coronary heart disease; among men, there were 164450 person-years of follow-up and 1063 cases of coronary heart disease.

† Continuous variable for increments of 1 serving/d using the median value for the quintile of intake.

¥ Distribution based on questionnaires from 1986 .

$\S$ Reference category (lowest quintile of intake).

\section{Discussion}

Our results suggest an inverse association between fruit and vegetable intake and risk for coronary heart disease in women and men. Intake of green leafy vegetables and vitamin $\mathrm{C}$-rich fruits and vegetables was inversely related to risk for coronary heart disease in both cohorts. These findings are similar to our previous find- ings for ischemic stroke (7). Fruit and vegetable intake beyond 4 servings/d was associated with a slight and nonsignificant decreased risk for coronary heart disease, and further reduction in risk seemed to occur in persons who consumed 8 or more servings daily. Adjustment for smoking attenuated the observed associations among women but had much less effect among men because 
the rates of smoking were very low among men. Significant associations still persisted after adjustment for other potential confounders. The cohorts were relatively homogenous with respect to education and occupation; hence, confounding by socioeconomic status was minimized.

Surprisingly few epidemiologic studies have examined the relationship between intake of vegetables and fruits and risk for coronary heart disease. Of the 16 prospective cohort studies reviewed by Ness and Powles (6), only $3(2,20,21)$ reported associations with intake of vegetables or fruits; other studies reported associations with nutrients that could serve as proxies, such as vitamin $C$ and $\beta$-carotene. In a study conducted in Japan (20), no significant association was found between intake of green and yellow vegetables and coronary heart disease. In the Adventist Health Study (21), no significant association was found for the total amount of fruit consumed, although inverse associations were found for consumption of nuts and whole-grain products. In a study of 5133 Finnish men and women, Knekt and colleagues (3) found an inverse association between intake of both vegetables and fruits assessed by using dietary history and subsequent death from coronary heart disease. When the highest and lowest tertiles of vegetable intake were compared, the multivariate relative risks for death from coronary heart disease were 0.66 (CI, 0.46 to 0.96 ) for men and 0.66 (CI, 0.35 to 1.23 ) for women. The relative risks comparing the highest and lowest tertiles of fruit intake were 0.77 (CI, 0.52 to 1.12 ) for men and 0.66 (CI, 0.36 to 1.22 ) for women. Inverse associations were observed for dietary intake of vitamins $\mathrm{E}$ and $\mathrm{C}$. In a subsequent report (4), the investigators found significant inverse associations between flavonoid intake and major food sources of flavonoid, including apple, berries, and onion, and death from coronary heart disease. In the Framingham Heart Study (22), a significant inverse association was observed between total vegetable and fruit consumption, as assessed by a single 24-hour recall instrument, and incidence of ischemic stroke among 832 men. However, this study did not report associations for coronary heart disease. A recent trial (23) of persons with established coronary heart disease showed that a Mediterranean diet rich in fruits and vegetables and $\alpha$-linolenic acid substantially reduced recurrence of coronary heart disease events for

\section{Figure. Total intake of fruits and vegetables and} multivariate relative risk for coronary heart disease.

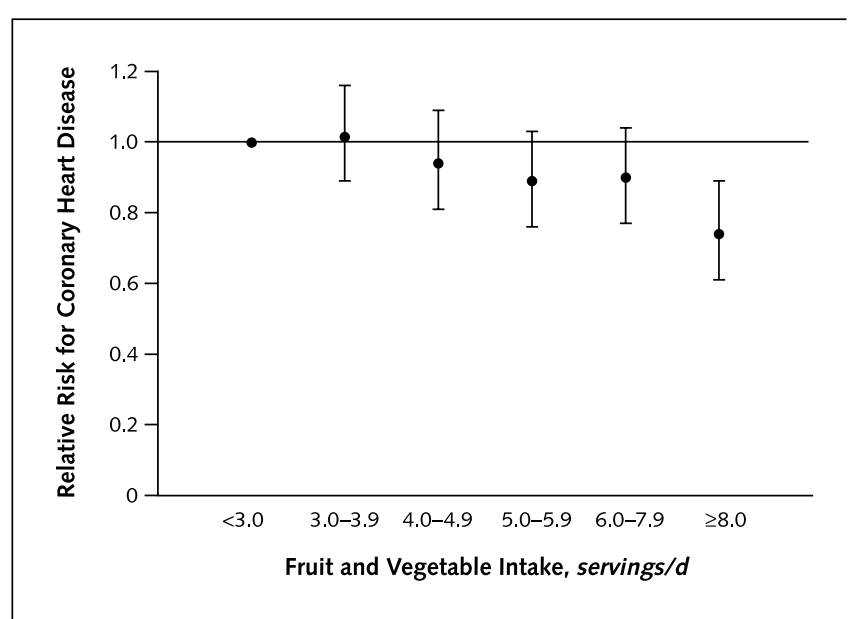

Data are for men and women combined and are adjusted for age (5-year categories), smoking status (never, former, or current [1-14, 15-24, or $>24$ cigarettes/d]), alcohol intake (7 categories in men and 5 categories in women), family history of myocardial infarction (age $<60$ years in men and $<65$ years in women), body mass index (quintiles), vitamin supplement use, vitamin E use, physical activity, aspirin use, 2-year follow-up period, presence of hypertension, presence of hypercholesterolemia, total daily caloric intake, and postmenopausal hormone use (among women). Fewer than 3 servings/d is the referent group. The trend in decreasing coronary heart disease risk with increasing fruit and vegetable intake, using a single continuous variable for the median intake in each quintile of the composite item and pooled across cohorts, is significant $(P=0.01)$. Error bars represent $95 \%$ CIs. $P$ for trend $=0.01$.

up to 4 years compared with a regular low-fat diet (relative risk, 0.28 [CI, 0.15 to 0.53$]$ ).

The mechanisms through which vegetables and fruits protect against cardiovascular disease are likely to be multiple. The postulated beneficial constituents in fruits and vegetables include antioxidant vitamins, folate, fiber, and minerals such as potassium. In our previous study, a higher intake of folate and vitamin $\mathrm{B}_{6}$ was significantly associated with lower risk for coronary heart disease (24), perhaps through reduction of plasma homocysteine levels. Intake of vitamin E from supplements $(1,25)$ and diet (26) may also protect against coronary heart disease. Fiber intake has been consistently associated with lower risk for coronary heart disease (5, 27-29); these results have been most consistent for cereal fiber. In a dietary intervention study (30), a diet rich in fruits and vegetables significantly decreased blood pressure among 459 adults with borderline hypertension. A diet that is higher in vegetables and fruits can significantly increase the antioxidant capacity of serum

19 June $2001 \mid$ Annals of Internal Medicine $\mid$ Volume 134 - Number $12 \mid \mathbf{1 1 1 1}$ 
ARTICLE $\quad$ Effect of Fruit and Vegetable Intake on Risk for Coronary Heart Disease

Table 2. Multivariate Relative Risk for Coronary Heart Disease, by Multivitamin Use and Smoking Status*

\begin{tabular}{|c|c|c|c|c|c|c|c|c|}
\hline \multirow[t]{2}{*}{ Characteristic } & \multicolumn{2}{|c|}{$\begin{array}{l}\text { Participants Not Using } \\
\text { Multivitamin Supplements }\end{array}$} & \multicolumn{2}{|c|}{$\begin{array}{l}\text { Participants Using } \\
\text { Multivitamin Supplements }\end{array}$} & \multicolumn{2}{|c|}{ Never or Past Smokers } & \multicolumn{2}{|c|}{ Current Smokers } \\
\hline & $\begin{array}{l}\text { Incidence } \\
\text { of CHD }\end{array}$ & $\begin{array}{l}\text { Relative Risk for } \\
\text { CHD }(95 \% \mathrm{Cl})\end{array}$ & $\begin{array}{l}\text { Incidence } \\
\text { of CHD }\end{array}$ & $\begin{array}{l}\text { Relative Risk for } \\
\text { CHD }(95 \% \mathrm{Cl})\end{array}$ & $\begin{array}{l}\text { Incidence } \\
\text { of CHD }\end{array}$ & $\begin{array}{l}\text { Relative Risk for } \\
\text { CHD }(95 \% \mathrm{Cl})\end{array}$ & $\begin{array}{l}\text { Incidence } \\
\text { of CHD }\end{array}$ & $\begin{array}{l}\text { Relative Risk for } \\
\text { CHD }(95 \% \mathrm{Cl})\end{array}$ \\
\hline \multicolumn{9}{|l|}{ Women } \\
\hline Cases of CHD, n† & 686 & & 323 & & 601 & & 522 & \\
\hline $\begin{array}{l}\text { Person-years of } \\
\text { follow-up }\end{array}$ & 324343 & & 196689 & & 448397 & & 129219 & \\
\hline Cases of $\mathrm{CHD}, n^{\dagger}$ & 507 & & 406 & & 845 & & 186 & \\
\hline $\begin{array}{l}\text { Person-years of } \\
\text { follow-up }\end{array}$ & 78122 & & 68566 & & 142384 & & 15605 & \\
\hline Total cases, $n$ & 1193 & & 729 & & 1446 & & 708 & \\
\hline \multicolumn{9}{|l|}{ Fruit and vegetable intake } \\
\hline All fruits and vegetables & & $0.96(0.92-0.99)$ & & $0.98(0.94-1.02)$ & & $0.96(0.94-0.99)$ & & $0.95(0.91-1.00)$ \\
\hline All fruits & & $0.94(0.89-1.00)$ & & $0.94(0.87-1.00)$ & & $0.95(0.90-1.00)$ & & $0.93(0.86-1.00)$ \\
\hline $\begin{array}{l}\text { Vitamin C-rich fruits } \\
\text { and vegetables }\end{array}$ & & $0.94(0.87-1.02)$ & & $0.97(0.88-1.07)$ & & $0.94(0.88-1.01)$ & & $0.92(0.82-1.03)$ \\
\hline Legumes & & $1.10(0.52-2.32)$ & & $1.17(0.76-1.81)$ & & $1.04(0.76-1.43)$ & & $1.28(0.66-2.46)$ \\
\hline Potatoes & & $0.78(0.46-1.34)$ & & $1.27(0.93-1.73)$ & & $1.12(0.72-1.76)$ & & $0.93(0.42-2.06)$ \\
\hline
\end{tabular}

* Adjusted for age (5-year categories), smoking status (never, former, or current [1-14, 15-24, or >24 cigarettes/d]), alcohol intake ( 7 categories in men and 5 categories in women), family history of myocardial infarction (age $<60$ years in men and $<65$ years in women), body mass index (quintiles), vitamin supplement use, vitamin E use, physical activity, aspirin use, 2-year follow-up period, presence of hypertension, presence of hypercholesterolemia, total daily caloric intake, and postmenopausal hormone use (among women). CHD = coronary heart disease.

† People who did not consume multivitamins but consumed other supplements and those for whom data on smoking status were missing are excluded.

and protect against in vivo lipid peroxidation (31). A higher intake of potassium has been associated with decreased blood pressure (32) and lower rates of stroke (33), but no direct data are available for coronary heart disease.

As with ischemic stroke (7), we found slightly stronger inverse associations for coronary heart disease with higher consumption of vegetables and fruits among nonusers of multivitamin supplements compared with supplement users. This finding suggests that constituents of multivitamin supplements may contribute to the apparent protective effect of fruits and vegetables. Smoking did not clearly affect the relation of fruit and vegetable consumption to risk for coronary heart disease. Current smokers may benefit slightly more from eating more fruits and vegetables than do never-smokers or past smokers, although this could be due to chance variation. Overall, the possible beneficial effects of fruits and vegetables on risk for cardiovascular disease has a strong biological basis. Because any single constituent of fruits and vegetables may not fully explain the apparent beneficial association, it is important to continue to rec- ommend increased overall intake of fruits and vegetables. However, these data and our previous analyses of stroke (7) do not support beneficial effects of increased consumption of potatoes.

The unique sample of health professionals in our cohorts is both a strength (as it minimizes potential for confounding) and a limitation (as the sample is not representative of the general population). Although the absolute rates of coronary heart disease and intake of fruit and vegetable in our study may differ from those in the general population, the associations between fruits and vegetables and rates of coronary heart disease are expected to be similar in the general population. However, the relative and, especially, absolute effect sizes may not be entirely generalizable to the general population. We believe that we underestimated the effect of fruits and vegetables on coronary heart disease because of the inherent measurement error in dietary assessments. Methods to correct for measurement error that use cumulative averages from repeated measures are not currently available; published methods refer to diet assessed at a single point in time. However, our use of a cumulative 
Effect of Fruit and Vegetable Intake on Risk for Coronary Heart Disease ARTICLE

average based on repeated measures in this report reduces measurement error (18). Since ours is a cohort study and the dietary exposure measures were collected before the event occurred, we do not expect any systematic bias in the diet measurement.

Since results from any single epidemiologic study may not provide conclusive evidence, additional studies in other populations should be done. Further epidemiologic studies will be needed, since large long-term randomized, controlled trials of diet would be difficult to implement.

On the basis of our overall results, we estimate that for 1 person in our study sample of male health professionals ( 40 to 75 years of age) and female nurses (34 to 59 years of age) to avoid a coronary heart disease event (34), 1443 persons (CI, 96 to 5780 persons) would have to increase consumption of fruits and vegetables by 1 serving/d for 12 years. These estimates are largely dependent on characteristics of the study sample; hence, among a subgroup of older men from our sample, or in other samples with higher smoking rates, fewer people would have to increase consumption to prevent one event. The benefit of a $5 \%$ to $20 \%$ reduction in coronary heart disease by fruit and vegetable intake is somewhat less than that achieved with use of statin drugs, which provide about a $30 \%$ reduction in risk, but consumption of fruits and vegetables provides many other benefits and should complement rather than replace other means of risk reduction.

In conclusion, our data support a protective effect of greater consumption of fruits and vegetables, in particular green leafy vegetables and vitamin $\mathrm{C}$-rich fruits and vegetables, against risk for coronary heart disease. Our results provide further support for recommendations to consume an abundance of fruits and vegetables.

From Harvard School of Public Health, Harvard School of Dental Medicine, Channing Laboratory, Brigham and Women's Hospital, and Harvard Medical School, Boston, Massachusetts.

Grant Support: By grants HL34595, HL35464 and CA40356, CA55075, and DE12102 from the National Institute of Health and by the Office of Dietary Supplements and the Florida Department of Citrus.

Acknowledgments: The authors thank the participants of the Health Professionals' Follow-up Study and the Nurses' Health Study for their continued cooperation and participation; Al Wing, Mira Kaufman, Karen Corsano, and Marcia Goetsch for computer assistance; Jill Arnold, Betsy Frost-Hawes, Kerry Demers, Mitzi Wolff, Gary Chase, and Bar- bara Egan for assistance in the compilation of data; and Laura Sampson for maintaining the food composition tables.

Requests for Single Reprints: Kaumudi J. Joshipura, ScD, Department of Oral Health Policy and Epidemiology, Harvard School of Dental Medicine, 188 Longwood Avenue, Boston MA 02115.

Current Author Addresses: Drs. Joshipura, Hu, Manson, Stampfer, Rimm, Speizer, Colditz, Ascherio, Rosner, Speigelman, and Willett: Harvard School of Public Health, 677 Huntington Avenue, Boston, MA 02115.

Author Contributions: Conception and design: K.J. Joshipura, F.B. Hu, J.E. Manson, M.J. Stampfer, E.B. Rimm, F.E. Speizer, G. Colditz, A. Ascherio, W.C. Willett.

Analysis and interpretation of the data: K.J. Joshipura, F.B. Hu, J.E. Manson, M.J. Stampfer, E.B. Rimm, A. Ascherio, B. Rosner, D. Spiegelman, W.C. Willett.

Drafting of the article: K.J. Joshipura, F.B. Hu, W.C. Willett.

Critical revision of the article for important intellectual content: K.J. Joshipura, F.B. Hu, J.E. Manson, M.J. Stampfer, E.B. Rimm, A. Ascherio, B. Rosner, D. Spiegelman, W.C. Willett.

Final approval of the article: K.J. Joshipura, F.B. Hu, J.E. Manson, M.J. Stampfer, F.E. Speizer, G. Colditz, A. Ascherio, D. Spiegelman, W.C. Willett.

Provision of study materials or patients: M.J. Stampfer, E.B. Rimm, F.E. Speizer, G. Colditz.

Statistical expertise: K.J. Joshipura, B. Rosner, D. Spiegelman, W.C. Willett.

Obtaining of funding: K.J. Joshipura, J.E. Manson, E.B. Rimm, F.E. Speizer, G. Colditz, W.C. Willett.

Administrative, technical, or logistic support: K.J. Joshipura, E.B. Rimm, F.E. Speizer, G. Colditz, W.C. Willett.

Collection and assembly of data: M.J. Stampfer, E.B. Rimm, F.E. Speizer, G. Colditz, D. Spiegelman, W.C. Willett.

\section{References}

1. Rimm EB, Stampfer MJ, Ascherio A, Giovannucci E, Colditz GA, Willett WC. Vitamin E consumption and the risk of coronary heart disease in men. N Engl J Med. 1993;328:1450-6. [PMID: 8479464]

2. Khaw KT, Barrett-Connor E. Dietary potassium and stroke-associated mortality. A 12-year prospective population study. N Engl J Med. 1987;316:235-40. [PMID: 3796701]

3. Knekt P, Reunanen A, Järvinen R, Seppänen R, Heliövaara M, Aromaa A. Antioxidant vitamin intake and coronary mortality in a longitudinal population study. Am J Epidemiol. 1994;139:1180-9. [PMID: 8209876]

4. Knekt P, Jarvinen R, Reunanen A, Maatela J. Flavonoid intake and coronary mortality in Finland: a cohort study. BMJ. 1996;312:478-81. [PMID: 8597679] 5. Rimm EB, Ascherio A, Giovannucci E, Spiegelman D, Stampfer MJ, Willett WC. Vegetable, fruit, and cereal fiber intake and risk of coronary heart disease among men. JAMA. 1996;275:447-51. [PMID: 8627965]

6. Ness AR, Powles JW. Fruit and vegetables, and cardiovascular disease: a review. Int J Epidemiol. 1997;26:1-13. [PMID: 9126498]

7. Joshipura KJ, Ascherio A, Manson JE, Stampfer MJ, Rimm EB, Speizer FE, 
ARTICLE Effect of Fruit and Vegetable Intake on Risk for Coronary Heart Disease

et al. Fruit and vegetable intake in relation to risk of ischemic stroke. JAMA. 1999;282:1233-9. [PMID: 10517425]

8. Hu FB, Stampfer MJ, Manson JE, Rimm E, Colditz GA, Rosner BA, et al. Dietary fat intake and the risk of coronary heart disease in women. N Engl J Med. 1997;337:1491-9. [PMID: 9366580]

9. Rose GA, Blackburn H. Cardiovascular survey methods. In: WHO Monograph Series No. 58. Geneva: World Health Organization; 1982.

10. Stampfer MJ, Willett WC, Speizer FE, Dysert DC, Lipnick R, Rosner B, et al. Test of the National Death Index. Am J Epidemiol. 1984;119:837-9. [PMID: 6720679]

11. Rimm EB, Giovannucci EL, Stampfer MJ, Colditz GA, Litin LB, Willett WC. Reproducibility and validity of an expanded self-administered semiquantitative food frequency questionnaire among male health professionals. Am J Epidemiol. 1992;135:1114-26. [PMID: 1632423]

12. Salvini S, Hunter DJ, Sampson L, Stampfer MJ, Colditz GA, Rosner B, et al. Food-based validation of a dietary questionnaire: the effects of week-to-week variation in food consumption. Int J Epidemiol. 1989;18:858-67. [PMID: 2621022]

13. Feskanich D, Rimm EB, Giovannucci EL, Colditz GA, Stampfer MJ, Litin $\mathrm{LB}$, et al. Reproducibility and validity of food intake measurements from a semiquantitative food frequency questionnaire. J Am Diet Assoc. 1993;93:790-6. [PMID: 8320406]

14. Steinmetz KA, Potter JD, Folsom AR. Vegetables, fruit, and lung cancer in the Iowa Women's Health Study. Cancer Res. 1993;53:536-43. [PMID: 8425185]

15. Caan B, Hiatt RA, Owen AM. Mailed dietary surveys: response rates, error rates, and the effect of omitted food items on nutrient values. Epidemiology. 1991;2:430-6. [PMID: 1790195]

16. D'Agostino RB, Lee ML, Belanger AJ, Cupples LA, Anderson K, Kannel WB. Relation of pooled logistic regression to time dependent Cox regression analysis: the Framingham Heart Study. Stat Med. 1990;9:1501-15. [PMID: 2281238]

17. Willett W. Nutritional Epidemiology. 2nd ed. New York: Oxford Univ Pr; 1998.

18. Hu FB, Stampfer MJ, Rimm E, Ascherio A, Rosner BA, Spiegelman D, et al. Dietary fat and coronary heart disease: a comparison of approaches for adjusting for total energy intake and modeling repeated dietary measurements. Am J Epidemiol. 1999;149:531-40. [PMID: 10084242]

19. DerSimonian R, Laird N. Meta-analysis in clinical trials. Control Clin Trials. 1986;7:177-88. [PMID: 3802833]

20. Hirayama T. Nutrition and cancer-a large scale cohort study. Prog Clin Biol Res. 1986;206:299-311. [PMID: 3952095]
21. Fraser GE, Sabaté J, Beeson WL, Strahan TM. A possible protective effect of nut consumption on risk of coronary heart disease. The Adventist Health Study. Arch Intern Med. 1992;152:1416-24. [PMID: 1627021]

22. Gillman MW, Cupples LA, Gagnon D, Posner BM, Ellison RC, Castelli WP, et al. Protective effect of fruits and vegetables on development of stroke in men. JAMA. 1995;273:1113-7. [PMID: 7707599]

23. de Lorgeril M, Salen P, Martin JL, Monjaud I, Delaye J, Mamelle N. Mediterranean diet, traditional risk factors, and the rate of cardiovascular complications after myocardial infarction: final report of the Lyon Diet Heart Study. Circulation. 1999;99:779-85. [PMID: 9989963]

24. Rimm EB, Willett WC, Hu FB, Sampson L, Colditz GA, Manson JE, et al. Folate and vitamin $\mathrm{B}_{6}$ from diet and supplements in relation to risk of coronary heart disease among women. JAMA. 1998;279:359-64. [PMID: 9459468]

25. Stampfer MJ, Hennekens CH, Manson JE, Colditz GA, Rosner B, Willett WC. Vitamin E consumption and the risk of coronary disease in women. N Engl J Med. 1993;328:1444-9. [PMID: 8479463]

26. Kushi LH, Folsom AR, Prineas RJ, Mink PJ, Wu Y, Bostick RM. Dietary antioxidant vitamins and death from coronary heart disease in postmenopausal women. N Engl J Med. 1996;334:1156-62. [PMID: 8602181]

27. Morris JN, Marr JW, Clayton DG. Diet and heart: a postscript. Br Med J. 1977;2:1307-14. [PMID: 589165]

28. Kushi LH, Lew RA, Stare FJ, Ellison CR, el Lozy M, Bourke G, et al. Diet and 20-year mortality from coronary heart disease. The Ireland-Boston DietHeart Study. N Engl J Med. 1985;312:811-8. [PMID: 2983212]

29. Khaw KT, Barrett-Connor E. Dietary fiber and reduced ischemic heart disease mortality rates in men and women: a 12-year prospective study. Am J Epidemiol. 1987;126:1093-102. [PMID: 2825519]

30. Appel LJ, Moore TJ, Obarzanek E, Vollmer WM, Svetkey LP, Sacks FM, et al. A clinical trial of the effects of dietary patterns on blood pressure. DASH Collaborative Research Group. N Engl J Med. 1997;336:1117-24. [PMID: 9099655]

31. Miller ER, Appel LJ, Risby TH. Effect of dietary patterns on measures of lipid peroxidation: results from a randomized clinical trial. Circulation. 1998;98: 2390-5. [PMID: 9832483]

32. Ascherio A, Rimm EB, Giovannucci EL, Colditz GA, Rosner B, Willett WC, et al. A prospective study of nutritional factors and hypertension among US men. Circulation. 1992;86:1475-84. [PMID: 1330360]

33. Ascherio A, Rimm EB, Hernán MA, Giovannucci EL, Kawachi I, Stampfer MJ, et al. Intake of potassium, magnesium, calcium, and fiber and risk of stroke among US men. Circulation. 1998;98:1198-204. [PMID: 9743511]

34. Chatellier G, Zapletal E, Lemaitre D, Menard J, Degoulet P. The number needed to treat: a clinically useful nomogram in its proper context. BMJ. 1996; 312:426-9. [PMID: 8601116] 